\title{
Development of an Affective Interface for Promoting Employees' Work Motivation in a Routine Work
}

\author{
Hidenori Fujino, Hirotake Ishii, Hiroshi Shmoda \\ Graduate School of Energy Science, Kyoto University \\ Gokasyo, Uji, Kyoto, 611-0011, Japan \\ fujino@uji.energy.kyoto-u.ac.jp, hirotake@ieee.org, shimoda@energy.kyoto-u.ac.jp
}

\begin{abstract}
A routine work requires few skills, so employees can be skilled easily. Therefore, the productivity and the quality of work greatly depend on employees' work motivation. However, as a routine work is often not interesting to almost all employees originally, a method for promoting and keeping employees' work motivation is required for keeping or increasing the productivity and the quality of work. Therefore, the objective of this study is to develop the method for promoting employees' work motivation in a routine work especially with an affective interface and applying the persuasion technique.
\end{abstract}

\section{Introduction}

A routine work, for example assembling products in factories, monitoring displays for controlling large plants and office work of inputting numerical data for accounting money and so on, requires few skills ordinary and employees can be skilled easily, so the productivity and the quality of work greatly depend on employees' work motivation. However, as a routine work is often not interesting to almost all employees originally and the significance of the work is often not clear and not easy to understand, employees' work motivation is decreased easily. Therefore method for promoting and keeping employees' work motivation in a routine work effectively is required for keeping or increasing the productivity and the quality of work.

In this study, the authors aim at promoting their understandings to the significance of the work by an affective interface as effective and efficient way for promoting and keeping employees' work motivation in a routine work. Especially the authors think "work motivation" of "attitude to the work", so an affective interface is developed with applying the force compliance which is one of persuasion techniques based on the theory of the cognitive dissonance. 


\section{Proposed Model for Employees' Promoting Work Motivation}

\subsection{Direction of developing the method}

Motivation is generally related with three feels; the feel of autonomy or self determination to his behavior in the situation, the feel of competence like ability or pride to his behavior, and the feel of relatedness with the society through his behavior (Deci and Flaste, 1995;Gange and Deci, 2005). Especially in the context of work, the feel of autonomy and the feel of pride are connected with the feel of relatedness, so if employees could deeply understand the social significance of their work and feel the relatedness with the society strongly, their feels of autonomy and pride to their work would be improved. Since a monotonous work usually needs only a few special skills, they have already had the feels of ability. Therefore, even if the understandings of the social significance of their work are promoted, employees' work motivation would be increased or at least be kept. So the direction to develop the method for promoting employees' work motivation is toward developing the method for promoting the understandings of the social significance of their work.

\subsection{Overview of the process of attitude formation and persuasion technique}

Since it can be thought that employees' work motivation is appearance of the employees' attitude to their work, the persuasion techniques are seemed to be applicable to promote the understandings of the social significance of their work.

Generally, the attitude consist of the cognitive component, the affective component, and the action component (Katz,1960). The cognitive component works at the first step of the attitude formation. This component manages the perception of the object and the information related with it. The affective component works at the second step of the attitude formation. This component manages the evaluation of the perceived object and information according to the value system of the person, for example "like" or "dislike", "positive" or "negative" and so on. The action component works at the last step of the attitude formation. This component manages the action and behavior to the object which are observed outside actually. When the person can behave autonomously to an object, his attitude to the object is expressed in his behavior in that situation. Therefore, in the case that his behavior affects the object positively, his attitude to the object is also positive and oppositely in the case that his behavior affects negatively, his attitude to the object is also negative.

If a new object and new information are inputted to the person, they are handled with these components sequentially like Fig.1 and the attitude to the object is formed. Formed attitude is memorized in the memory system of the person.

Many persuasion techniques have been proposed already. Those techniques are classified according to the component which each technique approaches. Typical persuasion techniques are shown in Fig.1. 
Flow of attitude formation

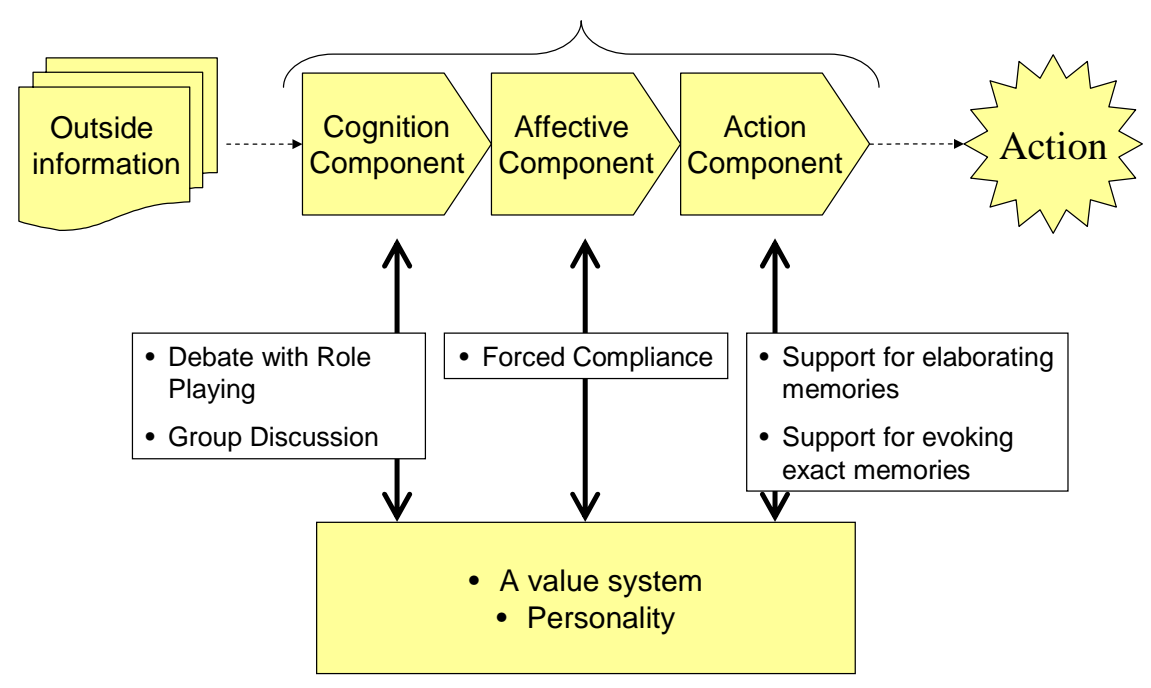

Fig. 1. The process of attitude formation and persuasion

\subsection{The methodology applying the theory of cognitive dissonance}

For promoting employees' understandings of the social significance of their work, it is necessary not only to show the information of rational reason that their work is significant for the society, but also to support that the information would be evaluated more positively because the person who has had low motivation to their work already would not necessarily evaluate that information positively. That is, support to approach the affective component is required.

In this study, therefore, the method to which "the force compliance" is applied, which is the persuasion technique based on the theory of cognitive dissonance (Festinger and Carlsmith, 1957). According to the theory of cognitive dissonance, when the person have the negative (or positive) attitude to an object and he behave to the object positively (or negatively), if he feel the strong stress of cognitive dissonance, he would change his own attitude from the negative to the positive (from the positive to the negative). Although having the negative (or positive) attitude to an object and behaving to the object positively (or negatively), if he feel only a little stress, for example because of large reward prepared for behaving so, his attitude would not be changed. For the prompting the strong stress of cognitive dissonance, it is necessary to make the person have the strong commitment to his own behavior.

The commitment is seemed to consist of three factors; the feel that the locus of the causality of his behavior is in himself, the publicness of his behavior, the impossibility of returning the state before his action (Kline and Peters, 1991). That is, when he thinks that he behave according to his own intention, when he thinks he would behave publicly, or when he thinks that the situation could not be returned to 
the state before his action be taken, he would have the strong commitment to his own behavior.

In conclusion, if it could be promoted to declare to others with rational reasons that his work is significant for the society for leading the feel of the impossibility of his behavior in the context of work for prompting his awareness of the publicness of his behavior and if the feel could be promoted that the locus of the causality of his behavior is in himself, he would be expected to evaluate the information positively that is the content of his own declaration and change his attitude to his work more positively, and to be more motivated to his work, because he would feel the strong stress of cognitive dissonance between his existing negative attitude and belief that his work is not significant and his own behavior that he declare to others that his work is significant.

\subsection{Proposed model}

In this section, the model is proposed which is the basis for practicing the measure based on the methodology designed in the previous section more efficiently and effectively.

Generally, a person has the tendency of finding the personality to the artificial object when it would behave like human, even if he has known that the object is artifact. Therefore, it is expected that even when he would declare it to social agents like animation characters that his work is significant for the society, he would have such a strong commitment to the action of declaration as when he declare to other

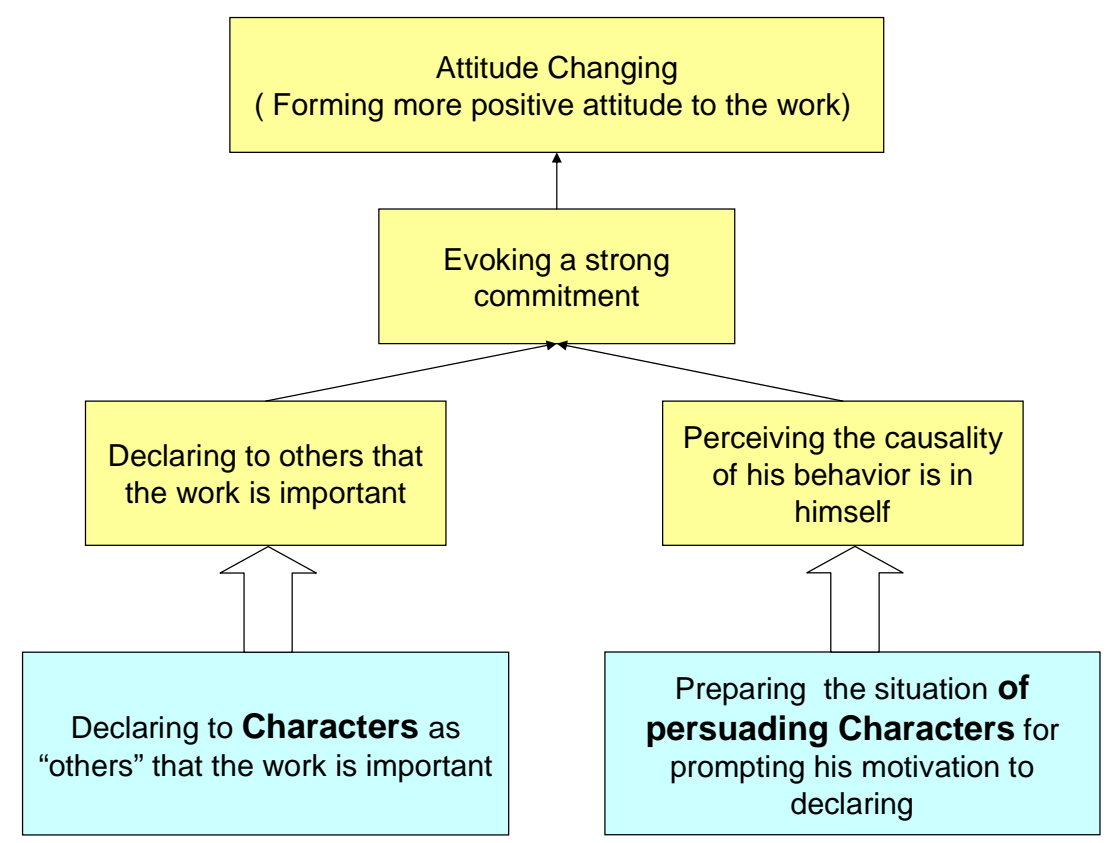

Fig. 2. Proposed model for promoting the understandings to the significance of the work 
persons.

Moreover, since a person has the need of competence, in other word, the achievement motive essentially (McClelland, 1961), if in the situation of game, a person would be motivated to make his best to get the good result of the game. Therefore, it is also expected that if it is possible to prepare the situation of connecting the action of declaration with the game, like persuasion, the person would be motivated to declaring that and feel the causality of his action of declaration is in himself.

The proposed model based on these considerations result is shown in fig. 2 .

In the next section, the experiment held for evaluating the validity of proposed model is explained.

\section{Experiment for Evaluating the Validity of Proposed Model}

\subsection{Design of Experiment}

\subsubsection{Method for evaluating the validity of proposed model}

The method for evaluating the validity of the model is firstly considered;

1. A simple and monotonous work is prepared and subjects engage in that work actually.

2. At a time during the work, subjects play the game based on the proposed model.

3. It is confirmed whether there is a difference measuring the attitude to the work before and after the game.

However, attitude changing is affected by not only playing the game but also other factors, for example, monotony of the work, experience to the work, and effect on elaboration of his memory about the significance of the work for considering the message whether he feel the strong stress of cognitive dissonance or not.

Therefore, since just the effect of the game to make subjects feel the strong stress of cognitive dissonance should be evaluated in this experiment, two following conditions is prepared and compared each other to confirm the effect of the game. First condition is the condition that subjects play the game based on the proposed model at the exact time during the work. This condition is called "Game Condition". Second condition is the condition that subjects input the message to tell the significance of the work to the prepared application which is very simple and in which any character is not displayed and any information about the result of persuasion is not returned to subject. This condition is called "Not Game Condition". After this, either playing the game in Game Condition or inputting the message in Not Game Condition is called "playing the game”.

\subsubsection{Questionnaire for measuring the attitude to the work}

The questionnaire prepared for measuring the attitude to the work is in table 1 . All subjects are required to answer this questionnaire on a scale from 1 to 7 where 1 
means “I don't think so at all” and 7 means "I think so strongly”. Actually, because the Cronbach alpha of this questionnaire is 0.74 which is calculated from the result of all answers of all subjects in the experiment, it is thought that there is the adequate consistency of this questionnaire.

Table 1. Questionnaire for measuring the attitude to the work

\begin{tabular}{|l|l|}
\hline Q.1 & Engaging in this work, Do you think that you are useful for the society? \\
\hline Q.2(inverse) & Engaging in this work, do you feel that you are rejected from the society? \\
\hline Q.3(inverse) & Engaging in this work, do you feel a strong mental stress? \\
\hline Q.4 & Is this work enjoyable for you? \\
\hline Q.5(inverse) & Do you feel that this work gets tired and boring easily? \\
\hline Q.6 & Are you proud to engage in this work? \\
\hline Q.7 & Do you feel that this work is significant for the society? \\
\hline Q.8(inverse) & $\begin{array}{l}\text { Do you think that you need not work hard because this work is not so } \\
\text { important? }\end{array}$ \\
\hline Q.9 & Are you interested in this work? \\
\hline Q.10(inverse) & $\begin{array}{l}\text { Do you think that your good performance isn't related with someone's } \\
\text { happiness even if you work hard? }\end{array}$ \\
\hline Q.11(inverse) & Engaging in this work, do you get irritated? \\
\hline
\end{tabular}

\subsubsection{Prepared works and subjects}

The work prepared for this experiment is to input the numerical dates which were written on papers by the hand and the dates consist of two kinds of dates. Subjects are explained with the backgrounds of these dates that each date were gathered in the quite different scene each other. All subjects are gathered in the condition of having experiences of engaging such a desk work by the temporary staffing agency.

Actually, subjects consisted of 15 women and 5 men. The oldest subject's age was 37 years old and the youngest subject's age was 21 years old. The average of all subjects' age was 30.5 and the S.D. was 4.6.

Considering the effect of learning the skill for the experimental tasks and of the order of the experimental tasks, subjects are grouped into four groups of 5 persons and subjects in each group engage in the experimental task according to the order shown by table 2 .

Table 2. The order of experimental task of each group

\begin{tabular}{|l|l|l|l|l|}
\hline & $\begin{array}{l}\text { Group 1 } \\
\text { (Subject1 5) }\end{array}$ & $\begin{array}{l}\text { Group 2 } \\
\text { (Subject6 10 } \\
\text { ) }\end{array}$ & $\begin{array}{l}\text { Group 3 } \\
\text { (Subject11 15) }\end{array}$ & $\begin{array}{l}\text { Group 4 } \\
\text { (Subject16 2 } \\
\text { 0) }\end{array}$ \\
\hline $\begin{array}{l}\text { Work and Condition } \\
\text { in the morning }\end{array}$ & $\begin{array}{l}\text { Work A and } \\
\text { Not Game }\end{array}$ & $\begin{array}{l}\text { Work A and } \\
\text { Game }\end{array}$ & $\begin{array}{l}\text { Work B and } \\
\text { Not Game }\end{array}$ & $\begin{array}{l}\text { Work B and } \\
\text { Game }\end{array}$ \\
\hline $\begin{array}{l}\text { Work and Condition } \\
\text { in the afternoon }\end{array}$ & $\begin{array}{l}\text { Work B and } \\
\text { Game }\end{array}$ & $\begin{array}{l}\text { Work B and } \\
\text { Not Game }\end{array}$ & $\begin{array}{l}\text { Work A and } \\
\text { Game }\end{array}$ & $\begin{array}{l}\text { Work B and } \\
\text { Not Game }\end{array}$ \\
\hline
\end{tabular}




\subsubsection{The flow chart of the experiment}

The time chart of the experiment is shown table.3. Although subjects should play the game for 40 minutes in each experimental condition according to this time chart, some subjects may finish the game in shorter. At that case, those subjects would be told to wait at his desk until next task after answering the questionnaire.

Table 3. Time table of the experiment

\begin{tabular}{|l|l|}
\hline $9: 00-9: 10$ & Briefly explaining the experiment \\
\hline $9: 10-9: 15$ & Explaining the work in the morning \\
\hline $9: 15-9: 20$ & 1st answering questionnaires about the work in the morning \\
\hline $9: 20-10: 10$ & Engaging in the work in the morning \\
\hline $10: 10-10: 15$ & 2nd answering questionnaires about the work in the morning \\
\hline $10: 15-10: 30$ & Engaging in the work in the morning \\
\hline $10: 30-10: 35$ & 3rd answering questionnaires about the work in the morning \\
\hline $10: 35-10: 40$ & The break time \\
\hline $10: 40-11: 20$ & Playing the Game ( Not Game ) \\
\hline $11: 20-11: 25$ & 4th answering questionnaires about the work in the morning \\
\hline $11: 25-12: 15$ & Engaging in the work in the morning \\
\hline $12: 15-12: 20$ & 5th answering questionnaires about the work in the morning \\
\hline $12: 20-12: 35$ & Engaging in the work in the morning \\
\hline $12: 35-12: 40$ & 6th answering questionnaires about the work in the morning \\
\hline $12: 40-13: 30$ & Lunch Time \\
\hline $13: 30-13: 40$ & Explaining the work in the afternoon \\
\hline $13: 40-13: 45$ & 1st answering questionnaires about the work in the afternoon \\
\hline $13: 45-14: 35$ & Engaging in the work in the afternoon \\
\hline $14: 35-14: 40$ & 2nd answering questionnaires about the work in the afternoon \\
\hline $14: 40-14: 55$ & Engaging in the work in the afternoon \\
\hline $14: 55-15: 00$ & 3rd answering questionnaires about the work in the afternoon \\
\hline $15: 00-15: 05$ & The break time \\
\hline $15: 05-15: 45$ & Playing the Not Game ( Game ) \\
\hline $15: 45-15: 50$ & 4th answering questionnaires about the work in the afternoon \\
\hline $15: 50-16: 40$ & Engaging in the work in the afternoon \\
\hline $16: 40-16: 45$ & 5th answering questionnaires about the work in the afternoon \\
\hline $16: 45-17: 00$ & Engaging in the work in the afternoon \\
\hline $17: 00-17: 05$ & 6th answering questionnaires about the work in the afternoon \\
\hline
\end{tabular}

The break time is prepared as shown, and if subjects want to go to the rest room for a few minutes, they can go freely even in any time.

\subsection{Construction of the system for the experiment}

\subsubsection{Game system}

The rule of the Game is as follow; there are 10 characters to be persuaded in the game and a subject are required to make a message explaining the significance of the work which would be done at that time to persuade each character. Subjects are explained that each character would remain in the game window if the significance of the work 
would be adequately expressed in subject's message, and also explained that in the other hand the character would be back if not.

Actually, however, all characters accept any message. The reasons for setting so is as follow;

- The algorism of this setting is very simple algorism, so the game system is constructed very easily.

- When the case would be prepared that the persuasion be failed, the impossibility of returning the state before his action would be weakened compared with the case of succeeding the persuasion.

- When he would fail the persuasion many times, the subject would come to be less motivated to the game autonomously because the need of competence of him could not be satisfied through playing the game. Moreover, the many time failure might lead the subject's self persuasion which would change his attitude to more negative one.

If subjects could play the game repeatedly, it has a rational reason to prepare such a case for the game being more challenging. Actually in this experiment, however, subjects play only one time because of controlling all subjects' experimental conditions so it is necessary to be such a setting.

The one scene of the game system is shown in Fig.3. In this scene, the bird character is the character to be persuaded. The clerk character is also shown in this scene. This character is the organizer of this game and manages the proceedings of the game. For example, she calls in the character one by one to be persuaded and introduces each character's personality to the subject. The characters to be persuaded do not speak anything and they only response the subjects' message. All the messages from the game system is spoken by the clerk character.

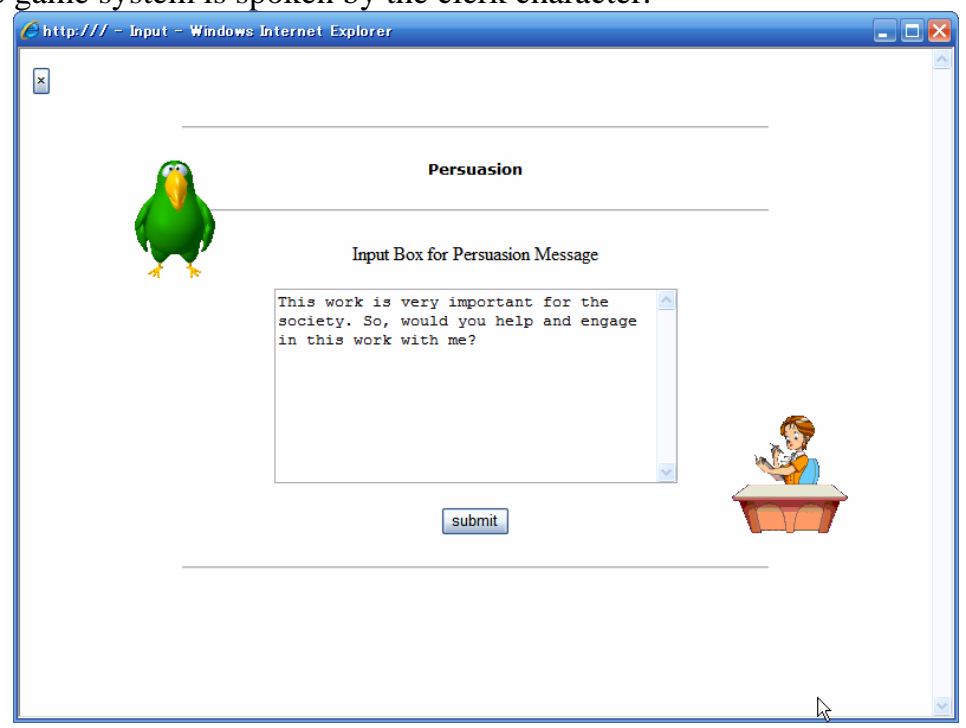

Fig. 3. Window of the Game system developed for the experiment.

Game started, the subjects need to persuade the characters one by one with referring the personality given by the clerk as a hint and. 


\subsubsection{Not Game system}

One scene of the system for the Not Game Condition, called Not Game system, is shown in Fig.4. A subject is needed to make the sentence of explaining the significance of the work which would be done at that time with referring the question sentence expressed in the window (following with Q.1 is the sentence in Fig.4) and input it to the textbox. It differs from the game that the character agent is not displayed at all, and that there is no feedback for the inputted sentence.

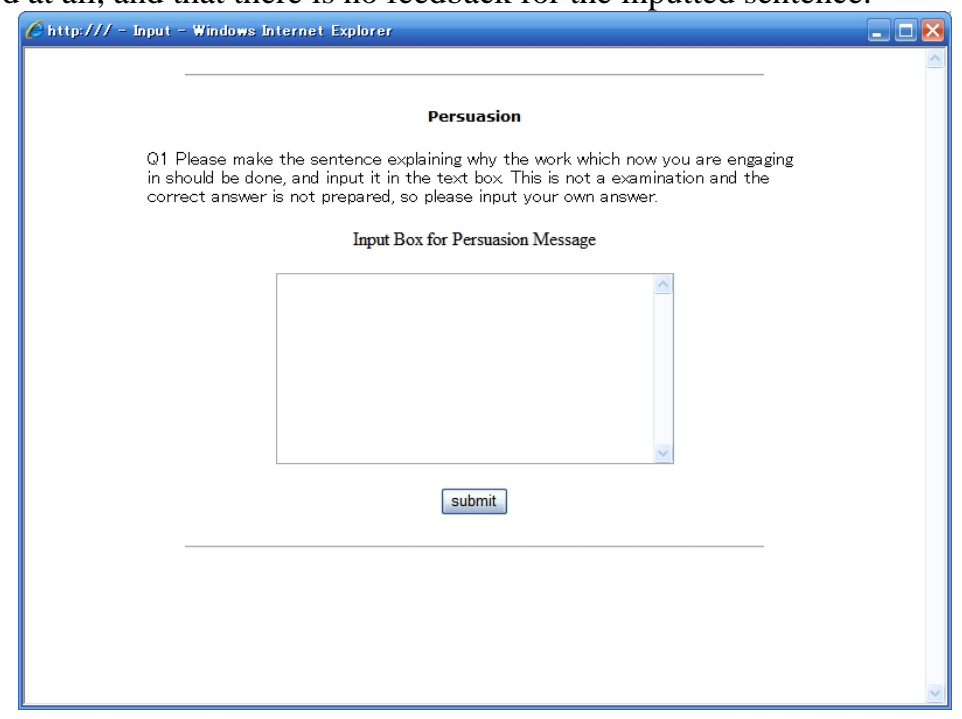

Fig. 4. Window of the Not Game system developed for the experiment

There are 10 questions in this system and each question is same meaning as the hint sentence given by the clerk character of the game as the character's personality. Actually it was confirmed by two university student that each the question sentence and each the hint sentence are same meanings.

\subsection{Result}

The result of the experiment is in table 4 . The averages are calculating by 15 subjects' differences of the score of the questionnaire before and after playing the Game.

5 subjects of 20 subjects were discarded for the following reasons;

- 3 subjects (2 subjects in Group 1 and 1 subject in Group 3) understood about the purpose of the experiment by mistak. They understood that the questionnaire is prepared for measuring not the attitude to "the work" which was done at that time, but the attitude to the "experiment".

- 1 subject in Group 3 forgot to answer the questionnaire at the time of 2nd answering questionnaires about the work in the morning.

- The results of both conditions of 1 subject in Group 4 were seemed to be outlier by the Thompson's test for finding outliers, $(\mathrm{t}=0.005<0.01$ in Game Condition, and $\mathrm{t}=0.007<0.01$ in Not Game Condition). 
Table 4. Average of all subjects' differences of the score of questionnaire before and after Game or Not Game ( $\mathbf{N}=15$ )

\begin{tabular}{lcccc}
\hline \hline Experimental Condition & Average & Variance & F test & $\begin{array}{c}\text { T test(One- } \\
\text { tail })\end{array}$ \\
\hline \hline Game & 1.93 & 3.77 & $0.32(>0.05)$ & $0.03(<0.05)$ \\
Not Game & -1.13 & 4.96 & & \\
\hline \hline
\end{tabular}

Obviously the average of the Game condition is significantly larger than the average of the Not Game condition. For this result, the Game system based on the proposed model is thought to promote subjects' attitude change effectively. This means that proposed model which consists of declaring to characters and preparing the situation of persuading characters is seemed to be valid as the model for promoting the understandings of significance of the work and promoting or at least keeping employees’ work motivation.

\section{Conclusion}

In this study, for the purpose of promoting employees' work motivation in a routine work which, the model for promoting the understandings of the significance of the work was proposed which is applied the theory of cognitive dissonance. Moreover, for evaluating the validity of the proposed model, the subjects experiment was conducted by the game system constructed based on the proposed model. As the result of the experiment, the subjects' attitude to the monotonous work in Game Condition was significantly positive compared with in Not Game Condition. Therefore, the validity of the proposed model was confirmed.

\section{Reference}

Deci,E.L. and Flaste,R. (1995) Why We Do What We Do: The dynamics of personal autonomy, G. P. Putnam Son’s, New York.

Gagne,M. and Deci,E.L. (2005) Self-determination theory and work motivation, Journal of Organizational Behavior, Vol.26, pp.331-362.

Katz,D. (1960) The functional approach to the study of attitudes, The Public Opinion Quarterly, Vol.24, No.2, pp.163 - 204.

Festinger,L. and Carlsmith, J.M. (1959) Cognitive consequences of forced compliance, Journal of Abnormal and Social Psychology, Vol.58, No.2, pp.203 - 210.

Kline,C. J. and Peters,L.H. (1991) Behavioral commitment and tenure of new employees: A replication and extension, Academy of Management Journal, Vol.34, pp.194-204.

McClelland,D.C. (1961) The achieving society. Princeton, NJ : Van Nostrand Reinhold. 